\title{
Chapter 52. Nuclear Microprobe Using Elastic Recoil Detection (Erd) For Hydrogen Profiling in High Temperature Protonic Conductors
}

1. Edgar Lara-Curzio,

2. Michael J. Readey

1. Pascal Berger ${ }^{1}$,

2. Ali Sayir ${ }^{2}$,

3. Marie-Hélène Berger ${ }^{3}$

Published Online: 26 MAR 2008

DOI: $10.1002 / 9780470291184 . \operatorname{ch} 52$

Copyright (C) 2004 The American Ceramic Society

Book Title

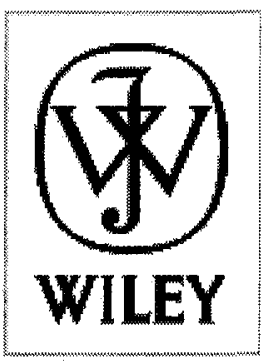

\section{8th International Conference on Advanced Ceramics and Composites A: Ceramic Engineering and Science Proceedings, Volume 25, Issue 3}

Additional Information

\section{How to Cite}

Berger, P., Sayir, A. and Berger, M.-H. (2008) Nuclear Microprobe Using Elastic Recoil Detection (Erd) For Hydrogen Profiling in High Temperature Protonic Conductors, in 28th International Conference on Advanced Ceramics and Composites A: Ceramic Engineering and Science Proceedings, Volume 25, Issue 3 (eds E. Lara-Curzio and M. J. Readey), John Wiley \& Sons, Inc., Hoboken, NJ, USA.

doi: 10.1002/9780470291184.ch52 
1 Laboratoire Pierre Süe, CEA-CNRS, CEA Saclay, 91191 Gif sur Yvette -FRANCE

2 NASA GRC/C.W.R.U. 21000 Brookpark Road Cleveland, 44135 OH- USA

3 Ecole des Mines des Paris, BP 8791003 Evry Cedex — FRANCE

\section{Publication History}

1. Published Online: 26 MAR 2008

2. Published Print: 1 JAN 2004

\section{Book Series:}

1. Ceramic Engineering and Science Proceedings (/bookseries/10.1002/SERIES2122)

\section{ISBN Information}

Print ISBN: 9780470051498

Online ISBN: 9780470291184

- Summary

- Chapter (/doi/10.1002/9780470291184.ch52/pdf)

- References (/doi/10.1002/9780470291184.ch52/references)

Get PDF (1963K) (/doi/10.1002/9780470291184.ch52/pdf)

\section{Keywords:}

HTPC; ERDA; RBS; PLXE; NRA

\section{Summary}

The interaction between hydrogen and various high temperature protonic conductors (HTPC) has not been clearly understood due to poor densification and unreacted secondary phases. the melt-processing technique is used in producing fully dense simple $\mathrm{SrCe}_{0.9} \mathrm{Y}_{0.1} \mathrm{O}_{3-\delta}$ and complex $\mathrm{Sr}_{3} \mathrm{Ca}{ }_{1+x} \mathrm{Nb}_{2+} \mathrm{O}_{9-\delta}$ perovskites that can not be achieved by solid-state sintering. the possibilities of ion beam analysis have been investigated to quantify hydrogen distribution in HTPC perovskites subjected to water heat treatment. Nuclear microprobe technique is based on the interactions of a focused ion beam of $\mathrm{MeV}$ light ions $\left({ }^{1} \mathrm{H},{ }^{2} \mathrm{H},{ }^{3} \mathrm{He},{ }^{4} \mathrm{He}\right.$,.) with the sample to be analyzed to determine local elemental concentrations at the $\mu \mathrm{m}^{3}$ scale. the elastic recoil detection analysis technique (ERDA) has been carried out using ${ }^{4} \mathrm{He}^{+}$ microbeams and detecting the resulting recoil protons. Mappings of longitudinal sections of water treated $\mathrm{SrCeO}_{3}$ and $\mathrm{Sr}\left(\mathrm{Ca}_{1 / 3} \mathrm{Nb}_{2 / 3}\right) \mathrm{O}_{3}$ perovskites have been achieved. the water treatment strongly alters the surface of simple $\mathrm{SrCe}_{0.9} \mathrm{Y}_{0.1} \mathrm{O}_{3-\delta}$ perovskite. From Rutherford Back Scattering measurements (RBS), both Ce depletion and surface re-deposition is evidenced. the ERDA investigations on water treated 
$\mathrm{Sr}_{3} \mathrm{Ca}_{1+x} \mathrm{Nb}_{2+x} \mathrm{O} 9-\delta$ perovskite did not exhibit any spatial difference for the hydrogen incorporation from the surface to the centre. the amount of hydrogen incorporation for $\mathrm{Sr}_{3} \mathrm{Ca}{ }_{1+x} \mathrm{Nb}_{2+x} \mathrm{O}_{9-\delta}$ was low and required further development of two less conventional techniques, ERDA in forward geometry and forward elastic diffusion ${ }^{1} \mathrm{H}(\mathrm{p}, \mathrm{p}){ }^{1} \mathrm{H}$ with coincidence detection.

Get PDF (1963K) (/doi/10.1002/9780470291184.ch52/pdf)

\section{More content like this}

Find more content:

- $\underline{\text { like this article (/advanced/search/results?articleDoi=10.1002/9780470291184.ch52\& }}$ $\underline{\text { scope }=\text { allContent } \& \text { start }=1 \text { \&resultsPerPage }=20 \text { ) }}$

Find more content written by:

- Pascal Berger (/advanced/search/results?searchRowCriteria[0].queryString="Pascal Berger"\&searchRowCriteria[0].fieldName=author\&start=1\&resultsPerPage=20)

- Ali Sayir (/advanced/search/results?searchRowCriteria[0].queryString="Ali Sayir"\&searchRowCriteria[0].fieldName=author\&start=1\&resultsPerPage=20)

- Marie-Hélène Berger (/advanced/search/results?searchRowCriteria[0].query String="Marie- । H\%C3\%A91\%C3\%A8ne Berger"\&searchRowCriteria[0].fieldName $=$ author\&start=1\& resultsPerPage $=20$ )

- All Authors (/advanced/search/results?searchRowCriteria[0].queryString="Pascal Berger" "Ali Sayir" "Marie-H\%C3\%A91\%C3\%A8ne Berger"\&searchRowCriteria[0].fieldName=author\& start $=1 \&$ resultsPerPage $=20$ ) 